Pacific Journal of Mathematics

AN EXAMPLE CONCERNING UNIFORM BOUNDEDNESS OF SH IO KAKUTANI 


\title{
AN EXAMPLE CONCERNING UNIFORM BOUNDEDNESS OF SPECTRAL MEASURES
}

\author{
SHIZUO KAKUTANI
}

1. Introduction. Let $X=\{x\}$ be a Banach space with a norm $\|x\|$. A bounded linear operator $E$ which maps $\nVdash$ into itself is called a projection if $E^{2}=E$. We do not require that $\|E\| \leq 1$, where

$$
\|E\|=\sup _{\|x\| \leq 1}\|E x\| .
$$

I et $B=\{\sigma\}$ be a Boolean algebra with a unit element 1. We denote the zero element of $B$ by 0 , and two fundamental operations in $B$ by $\sigma_{1} \cup \sigma_{2}$ and $\sigma_{1} \cap \sigma_{2}$. A family $\{E(\sigma) \mid \sigma \in B\}$ of projections $E(\sigma)$ of $X$ into itself is called an $X$ spectral measure on $B$ if the following conditions are satisfied: (i) $E(0)=$ 0 (=zero operator), (ii) $E(1)=1$ (= unit operator), (iii) $E\left(\sigma_{1} \cap \sigma_{2}\right)=E\left(\sigma_{1}\right) E\left(\sigma_{2}\right)$ for any $\sigma_{1}, \sigma_{2} \in B$, (iv) $\sigma_{1} \cap \sigma_{2}=0$ implies $E\left(\sigma_{1} \cup \sigma_{2}\right)=E\left(\sigma_{1}\right)+E\left(\sigma_{2}\right)$. An X-spectral measure $\{E(\sigma) \mid \sigma \in B\}$ is said to be uniformly bounded if there exists a constant $K<\propto$ such that $\|E(\sigma)\| \leq K$ for all $\sigma \in \mathbb{B}$.

Let $B=\{\sigma\}, B^{\prime}=\left\{\sigma^{\prime}\right\}$ be two Boolean algebras with a unit element, and let $B^{*}=B \otimes B^{\prime}$ be the Kronecker product of $B$ and $B^{\prime}$. Now $B^{*}$ may be considered as the Boolean algebra of all open-closed subsets $\sigma^{*}$ of $S^{*}$, where $S^{*}=S \times S^{\prime}$ is the topological Cartesian product of two Stone representation spaces $S, S^{\circ}$ of $B, B^{\prime}$, respectively. Every element $\sigma^{*} \in B^{*}$ is expressible in the form:

$$
\sigma^{*}=\bigcup_{i=1}^{n} \sigma_{i} \times \sigma_{i}^{\prime},
$$

where $\sigma_{i} \in \mathbb{B}, \sigma_{i}^{\prime} \in \mathbb{B}^{\prime} \quad(i=1, \cdots, n)$.

Let $\left\{E(\sigma) \mid \sigma \in \mathbb{R}^{\prime}\right\}$ and $\left\{E^{\prime}\left(\sigma^{\prime}\right) \mid \sigma^{\prime} \in \mathbb{B}^{\prime}\right\}$ be two $\mathcal{X}$-spectral measures on $B, B^{\prime}$, respectively, which are commutative with each other; that is,

$$
E(\sigma) E^{\prime}\left(\sigma^{\prime}\right)=E^{\prime}\left(\sigma^{\prime}\right) E(\sigma)
$$

Received March 4, 1953.

Pacific J. Math. 4 (1954), 363-372 
for any $\sigma \in B, \sigma^{\prime} \in R^{\prime}$. Let us put

$$
F\left(\sigma^{*}\right)=\sum_{i=1}^{n} E\left(\sigma_{i}\right) E^{\prime}\left(\sigma_{i}^{\prime}\right)
$$

if $\sigma^{*} \in B^{*}$ is of the form $(1.1)$ and if $\sigma_{i} \times \sigma_{i}^{\prime}(i=1, \cdots, n)$ are disjoint. Then it is easy to see that $F\left(\sigma^{*}\right)$ is uniquely deterinined (although the expression (1.1) with disjoint $\sigma_{i} \times \sigma_{i}^{\prime}$ is not necessarily unique), and $\left\{F\left(\sigma^{*}\right) \mid \sigma^{*} \in B^{*}\right\}$ is an $\mathcal{X}$-spectral measure on $B^{*} ;\left\{F\left(\sigma^{*}\right) \mid \sigma^{*} \in R^{*}\right\}$ is called the direct profluct $\mathcal{X}$-spectral measure of $\{E(\sigma) \mid \sigma \in B\}$ and $\left\{E^{\prime}\left(\sigma^{\prime}\right) \mid \sigma^{\prime} \in \mathbb{R}^{\prime}\right\}$.

It was asked by N. Dunford [2] whether the uniform boundedness of $\{E(\sigma) \mid$ $\sigma \in B\}$ and $\left\{E^{\prime}\left(\sigma^{\prime}\right) \mid \sigma^{\prime} \in B^{\prime}\right\}$ implies that of $\left\{F\left(\sigma^{*}\right) \mid \sigma^{*} \in R^{*}\right\}$. This question was answered in the affirmative by J. Wermer $[5]$ in case $\mathfrak{X}$ is a $: i_{i l b e r t}$ space. The main purpose of this note is to show that the answer is negative if $\mathcal{X}$ is a general Banach space; that is, we want to prove the following proposition:

Proposition. There exists a Banach space $\mathfrak{X}$ and a commutative pair of

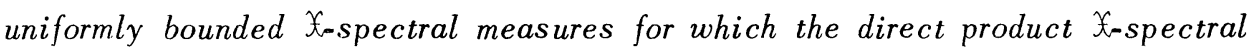
measure is not uniformly bounded.

Such an example will be given in $\S 3$. In our example, the Banach space $\mathfrak{X}$ is given as a cross product space $C(S) \circledast C\left(S^{\circ}\right)$ of two Banach spaces of continuous functions which will be defined in $\$ 2$. This Banach space is not reflexive and hence it remains open to decide whether the answer to the question is positive or negative in case $\mathfrak{X}$ is a reflexive Banach space.

2. The Banach space $C(S) \circledast C\left(S^{\prime}\right)$. Let $S=\{s\}, S^{\prime}=\left\{s^{\prime}\right\}$ be two compact Hausdorff spaces. Let $C(S), C\left(S^{\prime}\right)$ be the Banach spaces of all complex-valued continuous functions $y(s), z\left(s^{\prime}\right)$ defined on $S_{,} S^{\prime}$ with the norms

$$
\|y\|_{\infty}=\max _{s \in S}|y(s)|, \quad\|z\|_{\infty}=\max _{s^{\bullet} \in S^{\prime}}\left|z\left(s^{\prime}\right)\right| \text {. }
$$

Let

$$
S^{*}=S \times S^{\prime}=\left\{s^{*}=\left(s, s^{\prime}\right) \mid s \in S, s^{\prime} \in S^{\prime}\right\}
$$

be the topological Cartesian product of $S$ and $S^{\prime}$, and let $C\left(S^{*}\right)$ be the Banach space of all complex-valued continuous functions

$$
x\left(s^{*}\right)=x\left(s, s^{\prime}\right)
$$


defined on $S^{*}$ with the norm

$$
\|x\|_{\infty}=\max _{s^{*} \in S^{*}}\left|x\left(s^{*}\right)\right|
$$

Now $C(S), C\left(S^{\prime}\right)$ may be considered as closed linear sulspaces of $C\left(S^{*}\right)$ by identifying $y(s) \in C(S), z\left(s^{\prime}\right) \in C\left(S^{\prime}\right)$ wit ti $x\left(s, s^{\prime}\right) \in C\left(S^{*}\right)$ defined by

$$
x\left(s, s^{\prime}\right)=y(s), x\left(s, s^{\prime}\right)=z\left(s^{\prime}\right),
$$

respectively.

Consider $C\left(S^{*}\right)$ as a normed ring with the norm $\|x\|_{\infty}$. Then $C(S)$ and $C\left(S^{\prime}\right)$ are closed subrings of $C\left(S^{*}\right)$. Let $C(S) \otimes C\left(S^{\prime}\right)$ be the subring of $C\left(S^{*}\right)$ algebraically generated by $C(S)$ and $C\left(S^{\prime}\right)$; that is, the set of all functions $x\left(s, s^{\prime}\right) \in C\left(S^{*}\right)$ of the form:

$$
x\left(s, s^{\prime}\right)=\sum_{i=1}^{n} y_{i}(s) z_{i}\left(s^{\prime}\right),
$$

where $y_{i}(s) \in C(S), z_{i}\left(s^{\prime}\right) \in C\left(S^{\prime}\right) \quad(i=1, \cdots, n)$. From the Stone-ifeierstrass theorem it follows that $C(S) \otimes C\left(S^{\prime}\right)$ is dense in $C\left(S^{*}\right)$.

Let us now introduce a new norm on $C(S) \otimes C\left(S^{\prime}\right)$ defined by

$$
\|x\|=\inf \sum_{i=1}^{n}\left\|y_{i}\right\|_{\infty} \cdot\left\|z_{i}\right\|_{\infty}
$$

where inf is taken for all possible representations of $x\left(s, s^{\prime}\right) \in C(S) \otimes C\left(S^{\prime}\right)$ in the form (2.1).

It is easy to see that $\|x\| \|$ is a norm on $C(S) \otimes C\left(S^{\prime}\right)$ and satisfies

$$
\|x\|_{\infty} \leq\|x\|
$$

for all $x\left(s, s^{\prime}\right) \in C(S) \otimes C\left(S^{\prime}\right)$. Let $C(S) \circledast C\left(S^{\prime}\right)$ be the completion of $C(S) \otimes C\left(S^{\prime}\right)$ with respect to the norm $\|x\|$. The completion $C(S) \circledast C\left(S^{\prime}\right)$ is obtained from $C(S) \otimes C\left(S^{\prime}\right)$ by means of Cauchy sequences in $C(S) \otimes C\left(S^{\prime}\right)$ with respect to the norm $\|x \mid\|$. Since a Cauchy sequence with respect to $\|x\| \|$ is a Cauchy sequence with respect to $\|x\|_{\infty}$, we may consider $C(S) \circledast C\left(S^{\prime}\right)$ as a subset of $C\left(S^{*}\right)$ :

Lemma 1. Let $C(S) \circledast C\left(S^{\prime}\right)$ be the set of all functions $x_{0}\left(s^{*}\right) \in C\left(S^{*}\right)$ for which there exists a sequence $\left\{x_{n}\left(s^{*}\right) \mid n=1,2, \ldots\right\}$ of functions from 
$C(S) \otimes C\left(S^{\prime}\right)$ with the following properties:

(i) $\lim _{n \rightarrow \infty}\left\|x_{n}-x_{0}\right\|_{\infty}=0$, that is $\lim _{n \rightarrow \infty} x_{n}\left(s^{*}\right)=x_{0}^{*}(s)$ uniformly on $S^{*}$;

$$
\lim _{m, n \rightarrow \infty}\left\||| x_{m}-x_{n}\right\|=0 \text {, that is, }\left\{x_{n} \mid n=1,2, \cdots\right\}
$$

is a Cauchy sequence with respect to the norn \|\|$x \|$.

If we put

$$
\left\|x_{0}\right\|\left\|=\lim _{n \rightarrow \infty}\right\| \mid x_{n}\|\|,
$$

then $C(S) \circledast C\left(S^{\prime}\right)$ is a Banach space with respect to the norm $\||x \|| \mid$ and contains $C(S) \otimes C\left(S^{\prime}\right)$ as a dense subset.

The proof is easy and so it is omitted. It is interesting to observe that $C(S) \circledast C\left(S^{\prime}\right)$ is a normed ring with respect to the norm \|\|$x \|$.

$C(S) \circledast C\left(S^{\prime}\right)$ is called the minimal cross product Banach space of $C(S)$ and $C\left(S^{\prime}\right)$. It is easy to see that the minimal cross product Banach space

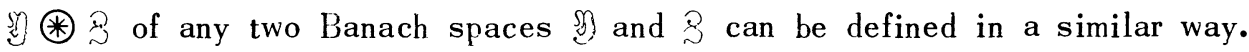
S $\odot$ is one of the cross product Banach spaces defined and discussed by R. Schatten and J. von Neumann $[\mathbf{3} ; \mathbf{4}]$.

3. Construction of an example. Let us now consider the case when both $S$ and $S^{\prime}$ are Cantor sets. Let $S=S^{\prime}$ be the set of all real numbers $s$ of the form

$$
s=2\left\{\frac{\epsilon_{1}(s)}{3}+\frac{\epsilon_{2}(s)}{3^{2}}+\cdots+\frac{\epsilon_{n}(s)}{3^{n}}+\cdots\right\},
$$

where $\epsilon_{n}(s)=0$ or $1(n=1,2, \cdots)$. I et $B=\{\sigma\}$ be the Boolean algebra of all open-closed subsets $\sigma$ of $S$.

Let $S^{*}=S \times S$ be the Cartesian product of $S$ with itself, and let $B^{*}=\left\{\sigma^{*}\right\}$ be the Boolean algebra of all open-closed subsets $\sigma^{*}$ of $S^{*}$. It is clear that $B^{*}=$ $B \otimes B$; that is, $B^{*}$ consists of all subsets $\sigma^{*}$ of $S^{*}$ which are expressible in the form (1.1), where $\sigma_{i}, \sigma_{i}^{i} \in B(i=1, \cdots, n)$.

For each $\sigma \in \mathbb{B}$, let $\phi_{\sigma}(s)$ be the characteristic function of $\sigma$, and put

$$
E(\sigma) x\left(s, s^{\prime}\right)=\phi_{\sigma}(s) x\left(s, s^{\prime}\right), E^{\prime}(\sigma) x\left(s, s^{\prime}\right)=\phi_{\sigma}\left(s^{\prime}\right) x\left(s, s^{\prime}\right) \text {. }
$$


It is clear that $E(\sigma), E^{\prime}(\sigma)$ are projections of $\mathcal{X}=C(S) \circledast C\left(S^{\prime}\right)$ into itself, and that $\{E(\sigma) \mid \sigma \in B\},\left\{E^{\prime}(\sigma) \mid \sigma \in \mathbb{B}\right\}$ are $\mathcal{X}$-spectral measures on $B$. Both of these spectral measures are uniformly bounded since $E(\sigma), E^{\prime}(\sigma)$ have norm 1 for any $\sigma \in B$ with $\sigma \neq 0$. Since

$$
E(\sigma) E^{\prime}\left(\sigma^{\prime}\right)=E^{\prime \prime}\left(\sigma^{\prime}\right) E(\sigma)
$$

for any $\sigma, \sigma^{\prime} \in B$, we can consider the direct product $X_{\text {-spectral measure }}$ $\left\{F\left(\sigma^{*}\right) \mid \sigma^{*} \in B^{*}\right\}$, defined on $B^{*}=B \otimes B$. We shall show that $\left\{F\left(\sigma^{*}\right) \mid \sigma^{*} \in B^{*}\right\}$ is not uniformly bounded.

Let us define a sequence of functions $\left\{\rho_{n}\left(s^{*}\right) \mid n=0,1,2, \cdots\right\}$ defined on $S^{*}=S \times S$ as follows: $\rho_{0}\left(s^{*}\right) \equiv 1$ on $S^{*}$, and

$$
\rho_{n}\left(s^{*}\right) \equiv \rho_{n}\left(s, s^{\prime}\right)=(-1)^{\sum_{k=1}^{n} \epsilon_{k}(s) \epsilon_{k}\left(s^{\prime}\right)}
$$

where $\epsilon_{k}(s)$ is the $k$ th coefficient in the expansion (3.1) of $s$. It is easy to see that $\rho_{n}\left(s^{*}\right)$ takes only the values \pm 1 and belongs to $C(S) \otimes C\left(S^{\prime}\right)$ for $n=0,1$, $2, \cdots$. Let us put

$$
\sigma_{n}^{*}=\left\{s^{*} \mid \rho_{n}\left(s^{*}\right)=1\right\} \quad(n=0,1,2, \cdots) .
$$

Then $o_{n}^{*} \in R^{*}$ for $n=0,1,2, \cdots$, and it is easy to see that

$$
\rho_{n}=\left(2 F\left(\sigma_{n}^{*}\right)-I\right) \rho_{0} \quad(n=0,1,2, \cdots) .
$$

Thus, in order to prove the proposition of $\$ 1$, it suffices to prove the following lemma:

Lemma 2. Let $S$ be the Cantor set. Let $\left\{\rho_{n}\left(s^{*}\right) \mid n=1,2, \cdots\right\}$ be a sequence of functions defined on $S^{*}=S \times S$ by (3.2). Then

$$
\lim _{n \rightarrow \infty}\|\| \rho_{n} \|=\infty
$$

where the norm $\left\|\rho_{n}\right\| \mid$ of $\rho_{n}$ is defined by (2.2).

In order to prove this lemma, let us put

$$
\tau(s)=\frac{\epsilon_{1}(s)}{2}+\frac{\epsilon_{2}(s)}{2^{2}}+\cdots+\frac{\epsilon_{n}(s)}{2^{n}}+\cdots \cdot
$$


Then $t=\tau(s)$ is a mapping of $S$ onto the closed unit interval

$$
I=\{t \mid 0 \leq t \leq 1\}
$$

which is one-to-one except for a countable set. I.et

$$
\mu(\sigma)=m(\tau(\sigma))
$$

be a measure defined on $B=\{\sigma\}$ which corresponds to the Lebesgue measure $m$ on $I$. Let us consider the $L^{2}$-space $L^{2}(S ; \mu)$ on $S$ with respect to the measure $\mu$, where the norm is given by

$$
\|y\|_{2}=\left\{\int_{S}|y(s)|^{2} \mu(d s)\right\}^{1 / 2} .
$$

Let $\sigma_{i}^{(n)}$ be the open-closed subset of $S$ consisting of all $s \in S$ such that

$$
\frac{\epsilon_{1}(s)}{2}+\cdots+\frac{\epsilon_{n}(s)}{2^{n}}=\frac{i-1}{2^{n}}
$$$$
\left(i=1, \cdots, 2^{n}\right) \text {. }
$$

Wie observe that

$$
\mu\left(\sigma_{i}^{(n)}\right)=2^{-n}
$$$$
\left(i=1, \cdots, 2^{n}\right)
$$

and that $\rho_{n}\left(s_{,} s^{\prime}\right)$ is constant $\left(=\epsilon_{i j}^{(n)}= \pm 1\right)$ on each $\sigma_{i}^{(n)} \times \sigma_{j}^{(n)}(i, j=1, \cdots$, $\left.2^{n}\right)$. Further, if we put

$$
\rho_{j}^{(n)}(s)=\rho_{n}\left(s, s^{\prime}\right)
$$

for $s \in S$ and $s^{\prime} \in \sigma_{j}^{(n)} \quad\left(j=1, \cdots, 2^{n}\right)$, that is, $\rho_{j}^{(n)}(s)=\epsilon_{i j}^{(n)}$ if $s \in \sigma_{i}^{(n)}$, then the functions $\rho_{j}^{(n)}(s) \quad\left(j=1, \cdots, 2^{n}\right)$ form an ortho-normal set in $L^{2}(S ; \mu)$. Consequently, by Bessel's inequality,

$$
\begin{aligned}
& \int_{S}\left|\int_{S} \rho_{n}\left(s_{>} s^{\prime}\right) y(s) \mu(d s)\right|^{2} \mu\left(d s^{\prime}\right) \\
& \quad=\frac{1}{2^{n}} \sum_{j=1}^{2^{n}}\left|\int_{S} \rho_{j}^{(n)}(s) y(s) \mu(d s)\right|^{2} \\
& \leq \frac{1}{2^{n}}\|y\|_{2}^{2}
\end{aligned}
$$


for any $y(s) \in L^{2}(S ; \mu)$. From this it follows that

$$
\begin{aligned}
\mid \int_{S} & \left.\int_{S} \rho_{n}\left(s, s^{\prime}\right) y(s) z\left(s^{\prime}\right) \mu(d s) \mu\left(d s^{\prime}\right)\right|^{2} \\
& \leqq\left\{\int_{S}\left|\int_{S} \rho_{n}\left(s, s^{\prime}\right) y(s) \mu(d s)\right| \cdot\left|z\left(s^{\prime}\right)\right| \mu\left(d s^{\prime}\right)\right\}^{2} \\
& \leqq \int_{S}\left|\int_{S} \rho_{n}\left(s, s^{\prime}\right) y(s) \mu(d s)\right|^{2} \mu\left(d s^{\prime}\right) \cdot \int_{S}\left|z\left(s^{\prime}\right)\right|^{2} \mu\left(d s^{\prime}\right) \\
& \leqq \frac{1}{2^{n}} \cdot\|y\|_{2}^{2} \cdot\|z\|_{2}^{2} \\
& \leqq \frac{1}{2^{n}}\|y\|_{\infty}^{2} \cdot\|z\|_{\infty}^{2}
\end{aligned}
$$

for any $y(s), z(s) \in C(S)$. From (3.8) it follows further that

$$
\left|\int_{S} \int_{S} \rho_{n}\left(s, s^{\prime}\right) x\left(s, s^{\prime}\right) \mu(d s) \mu\left(d s^{\prime}\right)\right| \leqq \sqrt{\frac{1}{2^{n}}} \cdot\|\| x \|
$$

for any $x\left(s, s^{\prime}\right) \in C(S) \otimes C\left(S^{\prime}\right)$. Since

$$
\rho_{n}\left(s, s^{\prime}\right) \in C(S) \otimes C\left(S^{\prime}\right) \text { and }\left(\rho_{n}\left(s, s^{\prime}\right)\right)^{2}=1
$$

on $S \times S^{\prime}$, we obtain, by setting $x\left(s, s^{\prime}\right)=\rho_{n}\left(s, s^{\prime}\right)$ in $(3.9)$, that

$$
\left\|\rho_{n}\right\| \geq \sqrt{2^{n}}
$$$$
(n=1,2, \cdots),
$$

and hence $\lim _{n \rightarrow \infty}\|\| \rho_{n} \|=\infty$.

4. Remarks. Let us consider the bounded linear operators $T, T^{\prime}$ defined on $C(S) \circledast C\left(S^{\prime}\right)$ by

$$
\begin{aligned}
T x\left(s, s^{\prime}\right) & =f(s) x\left(s, s^{\prime}\right), \\
T^{\prime} x\left(s, s^{\prime}\right) & =f\left(s^{\prime}\right) x\left(s, s^{\prime}\right),
\end{aligned}
$$

where $f(s)$ is a continuous function defined on $S$ by

$$
f(s)=3\left\{\frac{\epsilon_{1}(s)}{4}+\frac{\epsilon_{2}(s)}{4^{2}}+\cdots+\frac{\epsilon_{n}(s)}{4^{n}}+\cdots\right\} .
$$


It is easy to see that $T, T^{\prime}$ are spectral operators of scalar type and are given by

$$
T=\int_{S} f(s) E(d s),
$$

$$
T^{\prime}=\int_{S} f\left(s^{\prime}\right) E^{\prime}\left(d s^{\prime}\right)
$$

where $\{E(\sigma) \mid \sigma \in B\}$ and $\left\{E^{\prime}(\sigma) \mid \sigma \in B\right\}$ are a commutative pair of uniformly bounded spectral measures defined in $\S 3$.

It is possible to show that $T+T^{\prime}$ is not a spectral operator of scalar type. In order to show this we first observe that the range $S^{* *}$ of $f(s)+f\left(s^{\prime}\right)$ on $S^{*}=S \times S^{\prime}$ is a totally disconnected set. Let $B_{0}^{*}$ be the Boolean algebra of all open-closed subsets $\sigma^{*}$ of $S^{*}$ os the form:

$$
\sigma^{*}=\left\{s^{*}=\left(s, s^{\prime}\right) \mid f(s)+f\left(s^{\prime}\right) \in \sigma^{* *}\right\},
$$

where $\sigma^{* *}$ is an open-closed subset of $S^{* *}$. It suffices to show that the family of projections $\left\{F\left(\sigma^{*}\right) \mid \sigma^{*} \in B_{0}^{*}\right\}$ is not uniformly bounded.

For each $n$, let $\left\{\eta_{i}^{(n)} \mid i=1,2, \cdots\right\}$ be a sequence of period $2^{n}$; thus

$$
\eta_{i+2}^{(n)} n=\eta_{i}^{(n)}
$$$$
(i=1,2, \cdots) \text {. }
$$

Further, let the sequence consist only of +1 and -1 such that $\left(\eta_{i}^{(n)}, \ldots\right.$, $\left.\eta_{i+n-1}^{(n)}\right)$ runs through all $2^{n}$ different sequences of length $n$ consisting of +1 and -1 as $i$ runs through $1, \cdots, 2^{n}$. The existence of such a sequence was proved by N.G. de Bruijn $[\mathbf{1}]$. Let us put

$$
\pi_{n}\left(s^{*}\right)=\pi_{n}\left(s_{2} s^{\prime}\right)=\eta_{i+j-1}^{(n)},
$$

if $s \in \sigma_{i}^{(n)}, s^{\prime} \in \sigma_{j}^{(n)} \quad\left(i, j=1, \cdots, 2^{n}\right)$. Then $\left\{\pi_{n}\left(s^{*}\right) \mid n=1,2, \cdots\right\}$ is a sequence of functions from $C(S) \otimes C\left(S^{\prime}\right)$ taking only the values +1 and -1 such that the set

$$
\sigma_{n}^{*}=\left\{s^{*} \mid \pi_{n}\left(s^{*}\right)=+1\right\} \in \mathbb{B}_{0}^{*} \quad \text { for } n=1,2, \cdots
$$

Thus, by the same reason as in $\S 3$, it suffices to show that

$$
\lim _{n \rightarrow \infty}\left\|\pi_{n}\right\| \|=\infty
$$


I.et us put

$$
\pi_{j}^{(n)}(s)=\pi_{n}\left(s, s^{\prime}\right)
$$

if $s^{\prime} \in \sigma_{j}^{(n)}$. Then $\left\{\pi_{j}^{(n)}(s) \mid j=1, \cdots, 2^{n}\right\}$ is a set of functions from $L^{2}(S ; \mu)$ such that

$$
\left\{\pi_{i}^{(n)}(s), \cdots, \pi_{i+n-1}^{(n)}(s)\right\}
$$

is an orthonormal system for $i=1, \cdots, 2^{n}-n+1$. This follows from the fact that

$$
j+1 \leqq k \leqq j+n-1
$$

implies

$$
\begin{aligned}
& \int_{S} \pi_{j}^{(n)}(s) \pi_{k}^{(n)}(s) \mu(d s) \\
& =\frac{1}{2^{n}} \sum_{i=1}^{2^{n}} \eta_{i+j-1}^{(n)} \cdot \eta_{i+k-1}^{(n)}=0 .
\end{aligned}
$$

(The last equality holds because

$$
\eta_{i+j-1}^{(n)} \cdot \eta_{i+k-1}^{(n)}=+1
$$

happens $2^{n-1}$ times and

$$
\eta_{i+j-1}^{(n)} \cdot \eta_{i+k-1}^{(n)}=-1
$$

happens $2^{n-1}$ times as $i$ runs through $1, \cdots, 2^{n}$.)

Thus, for any $y \in L^{2}(S ; \mu)$, Bessel's inequality

$$
\sum_{j=i}^{i+n-1}\left|\int_{S} \pi_{j}^{(n)}(s) y(s) \mu(d s)\right|^{2} \leqq\|y\|_{2}^{2}
$$

holds for $i=1, \cdots, 2^{n}-n+1$, and hence 


$$
\begin{aligned}
& \int_{S}\left|\int_{S} \pi_{n}\left(s, s^{\prime}\right) y(s) \mu(d s)\right|^{2} \mu\left(d s^{\prime}\right) \\
& \quad=\frac{1}{2^{n}} \sum_{j=1}^{2^{n}}\left|\int_{S} \pi_{j}^{(n)}(s) y(s) \mu(d s)\right|^{2} \\
& \leqq \frac{1}{2^{n}}\left(\left[\frac{2^{n}}{n}\right]+1\right)\|y\|_{2}^{2} \\
& \leqq\left(\frac{1}{n}+\frac{1}{2^{n}}\right)\|y\|_{2}^{2} \leqq \frac{2}{n}\|y\|_{2}^{2} .
\end{aligned}
$$

From this follows, exactly as in $\S 3$, that

$$
\left|\int_{S} \int_{S} \pi_{n}\left(s, s^{\prime}\right) x\left(s_{s} s^{\prime}\right) \mu(d s) \mu\left(d s^{\prime}\right)\right| \leqq \sqrt{\frac{2}{n}}\|x\|
$$

for any $x\left(s, s^{\prime}\right) \in C(S) \otimes C\left(S^{\prime}\right)$, and hence

$$
|| \pi_{n}|| \geq \sqrt{\frac{n}{2}}
$$

for $n=1,2, \cdots$.

\section{REFERENCES}

1. N.G. de Bruijn, A combinatorial problem, Nederl. Akad. Wetensch., Proc. 49, ( 1946 ), 758-764, Indagationes Math. 8 ( 1946 ), 461-467.

2. N. Dunford, Spectral operators, Pacific J. Math. 4 ( 1954 ), 321 - 354.

3. R. Schatten and R. Schatten-J. von Neumann, The cross space of linear transformations I, II, III, Annals of Math. 47 (1946), 73-84, 608-630; 49 (1948), 557-582. 1950.

4. R. Schatten, A Theory of cross spaces, Annals of Math. Studies, No. 26, Princeton,

5. J. Wermer, Commuting spectral measures in a Hilbert space, Pacific J. Math. 4 ( 1954), $355-361$.

YALE UNIVERSITY 


\section{PACIFIC JOURNAL OF MATHEMATICS}

\section{EDITORS}

\author{
M.M. SCHIFFE R* \\ Stanford University \\ Stanford, California \\ E. HEWITT \\ University of Washington \\ Seattle 5, Washington
}

R.P. DILWORTH

California Institute of Technology Pasadena 4, California

E.F. BECKENBACH**

University of California

Los Angeles 24, California

\section{ASSOCIATE EDITORS}

$\begin{array}{llll}\text { H. BUSEMANN } & \text { P.R. HALMOS } & \text { BORGE JESSEN } & \text { J. J. STOKER } \\ \text { HERBERT FEDERER } & \text { HEINZ HOPF } & \text { PAUL LÉVY } & \text { E.G. STRAUS } \\ \text { MARSHALL HALL } & \text { R.D. JAMES } & \text { GEORGE PÓLYA } & \text { KÔSAKU YOSIDA }\end{array}$

\section{SPONSORS}

UNIVERSITY OF BRITISH COLUMBIA CALIFORNIA INSTITUTE OF TECHNOLOGY UNIVERSITY OF CALIFORNIA, BERKELEY UNIVERSITY OF CALIFORNIA, DAVIS UNIVERSITY OF CALIFORNIA, LOS ANGELES UNIVERSITY OF CALIFORNIA, SANTA BARBARA UNIVERSITY OF NEVADA OREGON STATE COLLEGE UNIVERSITY OF OREGON
UNIVERSITY OF SOUTHERN CALIFORNIA STANFORD RESEARCH INSTITUTE STANFORD UNIVERSITY WASHINGTON STATE COLLEGE UNIVERSITY OF WASHINGTON

AMERICAN MATHEMATICAL SOCIETY HUGHES AIRCRAFT COMPANY

Mathematical papers intended for publication in the Pacific Journal of Mathematics should be typewritten (double spaced), and the author should keep a complete copy. Manuscripts may be sent to any of the editors. Manuscripts intended for the outgoing editors should be sent to their successors. All other communications to the editors should be addressed to the managing editor, E.G. Straus, at the University of California Los Angeles 24, California.

50 reprints of each article are furnished free of charge; additional copies may be obtained at cost in multiples of 50 .

The Pacific Journal of Mathematics is published quarterly, in March, June, September, and December. The price per volume (4 numbers) is $\$ 12.00$; single issues, $\$ 3.50$; back numbers (Volumes $1,2,3$ ) are available at $\$ 2.50$ per copy. Special price to individual faculty members of supporting institutions and to individual members of the American Mathematical Society: $\$ 4.00$ per volume; single issues, $\$ 1.25$.

Subscriptions, orders for back numbers, and changes of address should be sent to the publishers, University of California Press, Berkeley 4, California.

Printed at Ann Arbor, Michigan. Entered as second class matter at the Post Office, Berkeley, California.

* To be succeeded in 1955, by H.L. Royden, Stanford University, Stanford, California.

** To be succeeded in 1955, by E.G. Straus, University of California, Los Angeles 24, Calif.

UNIVERSITY OF CALIFORNIA PRESS - BERKELEY AND LOS ANGELES 


\section{Pacific Journal of Mathematics \\ Vol. 4, No. $3 \quad$ July, 1954}

Nelson Dunford, Spectral operators ........................ 321

John Wermer, Commuting spectral measures on Hilbert space.......... 355

Shizuo Kakutani, An example concerning uniform boundedness of spectral measures...................................... 363

William George Bade, Unbounded spectral operators .............. 373

William George Bade, Weak and strong limits of spectral operators ...... 393

Jacob T. Schwartz, Perturbations of spectral operators, and applications. I. Bounded perturbations ........................... 415

Mischa Cotlar, On a theorem of Beurling and Kaplansky............... 459

George E. Forsythe, Asymptotic lower bounds for the frequencies of certain polygonal membranes ............................... 467 